\title{
The possible threats of labeling in a psychiatric
} context

\author{
Abstract \\ Labeling is a form of categorization which can have profound effects on individuals. In \\ psychiatric contexts, in which a form of categorization is utilized to discriminate and \\ identify mental disorders, this could lead to stigma and other negative consequences. \\ In this article I am identifying a relationship with the analytical viewpoints applied in \\ medical science and demonstrating the incongruence with psychiatric and psychological \\ perspectives. Most notably, I am stressing the negative effects these viewpoints may well \\ have on mental healthcare clients. But I am also pointing out some positive changes already \\ set in motion.
}

Volume 2 Issue 4 - 2015

\section{Marcel van Delft}

Psychologist, Netherlands

\author{
Correspondence: Marcel van Delft, Scharstraat 17, 46I7AL, \\ Bergen op Zoom, The Netherlands, \\ Email marcel_van_delft@hotmail.com
}

Received: August 13,2014 | Published: April 06, 2015

Keywords: psychiatry, labeling, stigma, psychiatric labeling, mental disorders, mental illness, mindfulness, medical science

\section{Introduction}

'You are such a smart child!'

We all know how proud parents can be when their children perform according to, or above expectations. And most of us are familiar with cases of people over estimating their offspring's talents. ${ }^{1}$ We only need to watch popular television programs like 'America's Got Talent', or talk to a representative person of a school for highly gifted children.

The expectations of adults may well be projected from their own inner psychological experience and needs.,3 And by calling their son or daughter 'smart', 'sweet', or 'difficult', they might already be labeling their personalities and capacities.

And as soon as children go to school, they will be labeled by others too: teachers, peers, other parents. Nicknames and other labels can range from seemingly innocent to really offensive, like 'dumb-ass' or 'fatso'. It is needless to say that these can really lower a person's self-esteem. ${ }^{4}$

Admittedly, it is not within the scope of this article to discuss all the different types of labeling, as the main focus is on psychiatric labeling. However, it serves the reader to demonstrate that labeling together with its positive and negative effects, occurs not only in the psychiatric setting.

In the broader context-society-labeling is applied too. People breaking the law are categorized as 'criminals' and have a hard time fighting their negative images even years after they have repented and re-entered society. ${ }^{5}$ Cultural minorities are suffering from consciously and subconsciously uttered stereotypes. ${ }^{6}$ This stereotyping might well be further facilitated and multiplied by means of modern social media. ${ }^{7}$ In some extreme cases, suspects of still unproven crimes-especially in the case of socially sensitive areas like pedophilia are crucified before being convicted. Even though research on this effect is scarce, one can imagine how it could devastate the involved persons' lives beyond repair.

\section{Labeling in psychiatry}

Many mental healthcare practitioners will probably agree that in psychiatric practice, labeling is applied too. ${ }^{8}$ The most commonly used guidebook for the diagnosis of mental 'illnesses', the Diagnostic and
Statistical Manual of mental disorders, has clearly defined categories and criteria to determine the specific syndrome or disorder a client is suffering from.

One could argue that this DSM-V originates from a medical point of view, in which analytical thinking and categorization is applied to outline specific illnesses, which require treatment. But although the evolution of clinical and scientific consensus regarding the framework underlying this widely used diagnostical tool does also prove beneficial, ${ }^{9}$ we may ask ourselves the question as to whether or not the medical view may be fully extrapolated to psychiatry. ${ }^{10}$

It could be defended that because mental illnesses are related to the mind - probably the most challenging research object to define and understand - the diagnosis and treatment of mental illnesses cannot be fully compared to the way medicine work on the organism when treating somatic diseases. ${ }^{11}$

Furthermore, the diagnosis and treatment of mental disorders is supposed to be scientifically grounded and many practitioners and legislators appear to be steering towards more evidence-based practices. ${ }^{12}$ However, I would like to stress that regardless of the advances in the modern techniques - for instance: neuroimaging used in psychological research and psychiatry, practitioners continue to depend on observations, interpretations, questionnaires and personal opinions. To determine whether or not a client suffers from depression, for instance, the practitioner needs to determine to what extent social life is interrupted and how severe the symptoms arewhich in my view involves mainly subjective interpretations. Whether or not science and practioners support this claim, it can be pointed out with some certainty that psychotherapy involves both specific and nonspecific factors. ${ }^{13}$

The problem is that institutions, governments and healthcare practitioners supporting the medical view, might ignore the fact that the mind is a complex system and that a person needs an individualized approach, taking into account more than just the diagnosis and a fixed diagnosis-treatment combination. ${ }^{13}$ In countries where healthcare is financed by insurance companies it is common to apply a cost-benefit approach if the total costs of healthcare are considered to be 'too high for society to bear'. Cost is among the many factors why so many clients in need of treatment stay away from healthcare providers. ${ }^{14}$ 
Other reasons reported in the mentioned research are: stigma, minimization, low perceived treatment effectiveness, and structural barriers. ${ }^{14}$ If I read this, I cannot help but thinking that a full dedication to evidence-based treatments in combination with a debatable system of diagnosis-inspired by the medical paradigm-might not be what healthcare, governments and insurance companies should be investing in. At least, not in the ratio that they are doing right now.

This is not to say that I oppose the implementation of evidencebased practices. Of course numerous clinicians and scientists provide reasonable arguments supporting the claim that the field of psychiatry greatly benefits from more evidence-based practice. ${ }^{12}$ However, regardless of these benefits, I would like to point out that there are possible negative consequences which need to be addressed, and taken into account by clinicians, governments, insurance companies and the media.

An important question is: how does the diagnosis of a mental disorder affect personality and self-image? For instance, what effect does a psychiatric label have on the way the applicable 'patient' perceives himself*? ${ }^{8}$

The treatment might reduce the initial symptoms and ensure that the person can function at a normal level professionally and socially. But will it help him to find a new purpose in his life? And what will his friends, colleagues and family say? ${ }^{15-17}$ The diagnostic labels used in psychiatry are not always fully understood and appreciated by the general public and it strikes me as very important that advocacy groups correct the negative images and explain the limited context in which the psychiatric terminology can be validly used. Luckily such initiatives are increasingly reported..$^{15}$

It must be stated though, that not all research results point towards negative effects of psychiatric labeling. In some studies, no significant effects have been found ${ }^{5,18,19}$ and in some cases diagnostic labels can help overcome clinicians' biases..$^{20}$

* When I write 'him' or 'he', it could equally imply 'her' or 'she'.

\section{Positive changes with regards to the negative consequences of psychiatric labeling}

Fortunately the image of the field of psychiatry is not as hopeless as it might seem from the perspective of those who, like me, are cautious in allowing the extrapolation of medical views and labeling to the psychiatric context.

The meta-study quoted earlier ${ }^{15}$ has shown that more and more advocacy groups are battling the negative image that psychiatric labels have in society. This does not mean that labels will be discarded altogether (an extreme I would also not support), but at least some of the negative consequences are being countered.

The advent of the mindfulness approach in my view also proves that psychiatry is broadening its horizon, ${ }^{21}$ allowing eastern philosophy to inspire a field which has been dominated by western analytical views for decades.

\section{Conclusion}

In the previous section I have tried to demonstrate the importance of labeling and its possible negative consequences - admitting that not all research supports this negative view.

Although labeling occurs in many situations for instance in family systems, at school and when people face ethnical minorities-it was beyond the scope of this article to discuss them all, focusing on the psychiatric context instead.
I went on to demonstrate that the main diagnostic tool used in psychiatry-the DSM-V is rooted in what I call the medical paradigm. I pointed out that the mind is a complex entity, which is why one should be cautious in using the labels used to diagnose clients.

When governments, insurance companies and the uninformed public use the terminology (labels) of psychiatry, especially in combination with a cost-benefit approach solely relying on evidencebased standardized treatments, this could scare away potential clients who are in dire need of personalized treatments. In the previous section I have provided arguments and references to indicate that this is already happening - although I tried putting things in perspective by also referring to research demonstrating the importance and advantage of implementing evidence-based practices.

It is my opinion as a psychologist, supported by other practitioners in the field, that clients need to be treated with respect, the labels only used to facilitate the process of defining the focal point of attention in the treatment. Diagnostic labels, in my view, do not define a person and, in my opinion, should not be used outside the clinical context.In addition, I have been trying to convince the reader that when the clinical focus is mainly on diagnostic labels and evidencebased treatments, practioners might ignore the fact that every client is unique and could benefit more by a personalized treatment, with additional attention to finding a purpose in his life.

Luckily, I also found out that advocacy groups are trying to battle the stigma of psychiatric patients. And the rise of mindfulness based treatments also demonstrates that the field is broadening its horizons. These developments might compensate for what I consider to be 'the damage caused by the the unilateral implementation of the analytical framework of the medical establishment'. Clients are persons, not labels, and when they struggle with mental Issues, these labels may only be used to help clinicians determine the focal point of attention, but always taking into account the unicity of the person, context and his needs in every aspect of his life.

I would like to recommend to spend more budget on research in this area, as valuable findings on this topic are still scarce. In addition, both practitioners as public institutions and groups should educate the public, governments and the (insurance)companies responsible for funding healthcare.

\section{Acknowledgments}

None.

\section{Conflicts of interest}

Author declares there are no conflicts of interest.

\section{Funding}

None.

\section{Referencess}

1. Brummelman E, Thomaes Sander, Nelemans SA, et al. My Child Is God's Gift to Humanity: Development and Validation of the Parental Overvaluation Scale (POS). Journal of Personality and Social Psychology. 2014.

2. Felson, Richard B. Parents and the reflected appraisal process: A longitudinal analysis. Journal of Personality and Social Psychology Vol. 1989;56(6):965-971.

3. Foster, Randall M, Lomas Donald F. Anger, disability, and demands in the family. American Journal of Orthopsychiatry. 1978; 48(2):228-236. 
4. Haltigan John D, Vaillancourt Tracy. Joint trajectories of bullying and peer victimization across elementary and middle school and associations with symptoms of psychopathology. Dev Psychol. 2014;50(11):2426-2436.

5. Chassin Laurie, Presson Clark C, Young Richard D, et al. Self-concepts of institutionalized adolescents: A framework for conceptualizing labeling effects. J Abnorm Psychol. 1981;90(2):143-151.

6. Owuamalam Chuma Kevin, Zagefka Hanna. On the psychological barriers to the workplace: When and why metastereotyping undermines employability beliefs of women and ethnic minorities. Cultur Divers Ethnic Minor Psychol. 2014;20(4):521-528.

7. Barlett CP, Gentile DA. Attacking others online: The formation of cyberbullying in late adolescence. Psychology of Popular Media Culture. 2012;1(2):123-135.

8. Mansouri Lisa, Dowell David A. Perceptions of stigma among the long-term mentally ill. Psychosocial Rehabilitation Journal. 1989;13(1):79-91.

9. Wright AG, Calabrese WR, Rudick MM, et al. Stability of the DSM5 Section III pathological personality traits and their longitudinal associations with psychosocial functioning in personality disordered individuals. J Abnorm Psychol. 2015;124(1):199-207.

10. Goddard Murray J. Critical psychiatry, critical psychology, and the behaviorism of B. F. Skinner. Review of General Psychology. 2014;18(3):208-215.

11. Klein Stanley B. A Defense of Experiential Realism: The Need to Take Phenomenological Reality on Its Own Terms in the Study of the Mind. Psychology of Consciousness: Theory, Research, and Practice. 2015;2(1):41-56.

12. Bearman SK, Wadkins M, Bailin A, et al. Pre-practicum training in professional psychology to close the research-practice gap: Changing attitudes toward evidence-based practice. Train Educ Prof Psychol Vol. 2015;9(1):13-20.
13. Weinberger Joel. Common factors are not so common and specific factors are not so specified: Toward an inclusive integration of psychotherapy research. Psychotherapy. 2014;51(4):514-518.

14. Alang SM. Sociodemographic Disparities Associated With Perceived Causes of Unmet Need for Mental Health Care. Psychiatr Rehabil J [Epub ahead of print]. 2015.

15. Corrigan PW, Morris SB, Michaels PJ, et al. Challenging the Public Stigma of Mental Illness: A Meta Analysis of Outcome Studies. Psychiatr Serv. 2012;63(10):963-973.

16. Kravetz S, Faust M, Shalit M. The mental health of men with a psychiatric disorder or traumatic brain injury: Wives' labeling and husbands' perceived control. Rehabilitation Psychology. 2001;46(4):436-451.

17. Kravetz S, Faust M, David M. Accepting the mental illness label, perceived control over the illness, and quality of life. Psychiatric Rehabilitation Journal. 2000;23(4):323-332.

18. Boisvert Charles M, David F. Effects of the label "schizophrenia" on causal attributions of violence. Schizophrenia Bulletin. 1999;25(3):479-491.

19. Fernald CD, Williams Rebecca A, Droescher SD. Actions speak louder...: Effects of diagnostic labels and child behavior on perceptions of children. Professional Psychology: Research and Practice. 1985;16(5):648-660.

20. Davis DA. What's in a name? A Bayesian rethinking of attributional biases in clinical judgment. J Consult Clin Psychol. 1979;47(6):1109-1114.

21. Goldberg SB, Del Re AC, Hoyt WT, et al. The secret ingredient in mindfulness interventions? A case for practice quality over quantity. $J$ Couns Psychol. 2014;61(3):491-497. 